\title{
Some Features of an Inspiring Book; or: Why Sociologists Should Study Love Despite Its Intangibility*
}

ILLOUZ E. (2016). WHY LOVE HURTS: A SOCIOLOGICAL EXPLANATION. CAMBRIDGE: POLITY. 294 P. ISBN

978-0-745-67107-9

\author{
Irina Trotsuk \\ DSc (Sociology), Leading Research Fellow, Centre for Fundamental Sociology, \\ National Research University Higher School of Economics \\ Associate Professor, Department of Sociology, RUDN University \\ Address: Myasnitskaya str., 20, Moscow, Russian Federation 101000 \\ E-mail: irina.trotsuk@yandex.ru
}

What is love? 'Tis not hereafter;

Present mirth hath present laughter;

What's to come is still unsure:

In delay there lies not plenty;

Then, come kiss me, sweet and twenty,

Youth's a stuff will not endure.

William Shakespeare

Love hurts, love scars,

Love wounds and marks ...

Some fools think

Of happiness, blissfulness, togetherness,

Some fools fool themselves, I guess

They're not foolin' me

I know it isn't true

Love is just a lie made to make you blue.

Boudleaux Bryant

Love becomes no more than an exchange, with no binding rules except the obligation of full and open communication.

Robert Bellah et al. ${ }^{1}$

It is no secret that scholars love ${ }^{2}$ to attend conferences and meetings of all kinds not only to communicate and exchange scientific ideas and findings, but also to find out what is

(c) Irina Trotsuk, 2017

(C) Centre for Fundamental Sociology, 2017

DOI: $10.17323 / 1728-192 \mathrm{X}-2017-4-105-118$

* The publication of this paper is supported by the Basic Research Program of the National Research University Higher School of Economics.

1. Bellah R., Sullivan W., Swidler A., Tipton S. (1985). Habits of the Heart: Individualism and Commitment in American Life. Berkeley: University of California Press. P. 108.

2. Obviously, this word is to be frequent in a review of a book on love. 
new in the non-fiction book market and to hold new editions in their hands to make sure that the books chosen by the title are the "ones". Usually, the thematic repertoire of the books presented by publishing houses at sociological conferences is predictable for people attending such events or interested in the discipline in general, though surprises can happen. As a rule, the unexpectedness of titles is determined by the traditional topics of national sociological schools, topics that differ among the countries for objective reasons ${ }^{3}$ and the historical development of the national school ${ }^{4}$. This explains why the book titled Why Love Hurts ${ }^{5}$ seemed so unexpected and alien at the 13th Conference of the European Sociological Association “(Un)Making Europe. Capitalism, Solidarities, Subjectivities” (Athens, 2017) for a Russian scholar like me, because my educational and scientific background never let me consider such a topic sociologically relevant to the study of the transformations of contemporary society. Eva Illouz defines sociology in the context of romantic love as "a study of collective forms of sufferings: inequality, poverty, discrimination, diseases, political oppression, large-scale armed conflicts, and natural disasters are the main prism through which it has explored the agonies of the human condition. Sociology has been very successful in analyzing these collective forms of suffering, yet has neglected the analysis of ordinary psychic sufferings that inheres in social relationships... If sociology is to remain relevant to modern societies, it must imperatively explore the emotions that reflect the vulnerability of the self in conditions of late modernity that is at once institutional and emotional, ... which will take us back to the primary and still much needed ... vocation of sociology" (p. 15).

There are at least two extremely important concepts of everyday life that are too intangible for theoretical and empirical study - love and happiness. Or rather, the situation is ambivalent: we are well aware of our own happy moments and of falling in love (though happiness can be unexpected and inexplicable, and love can be rationalized as lust, passion, escape from loneliness, desire to prove something, etc.), but when researchers ask us simple questions about either of the two we often feel like idiots incapable of giving a verbal description of such close and self-evident things. Perhaps that is why love poetry has been so highly valued for centuries; providing us with the words for describing the virtues and dangers of love. Both were wonderfully expressed by Shakespeare: "What eyes hath love put in my head, / which have no correspondence with true sight: / or if they have, where is my judgment fled/ that censures falsely what they see aright? / If that be fair whereon my false eyes dote, / what means the world to say it is not so? / If it be not, then love doth well denote / love's eye is not so true as all men's: no, / how can it? O how can love's eye be true, / that is so vex'd with watching and with tears? . . / O cunning love! With tears thou keep'st me blind, / lest eyes well-seeing thy foul faults should find!"

3. Some social phenomena can be too underrepresented to be worth studying; some can be taboo such as sexual practices and different aspects of dying in Russia; some are traditionally ignored as irrelevant/insignificant despite their acuteness, such as abortion and ethnic conflict in Russia.

4. For instance, the sociology of emotions is not a developed branch in Russia because the relations between sociology and psychology are strained, and the "legitimate" sociological "borrowings" are more psychodiagnostic procedures and projective techniques adapted for the sociological analysis of social representations. 5. Unfortunately, I missed the first editions of the book in 2012, 2014 and 2015, so it is new for me. 
(Sonnet 148). Thus, Eva Illouz is strikingly brave to approach such an intangible and ambivalent object as love and to consider love a legitimate object of the sociological study.

I do not like the popular review style of a provocative enumeration of the book's characteristics, but this is exactly the case for otherwise the review would become too long (because the text is saturated with findings, data and quotes) and boring (the book is intriguing and full of illustrative examples, yet an attempt to fully reflect it in the review would tire the reader). There are many subtitles in the book but the list of contents is rather brief: it starts with an Introduction (Chapter 1) on the misery of love, i.e. on romantic pain, "the agonies of intimate relationships". The second chapter describes the great transformations of love ${ }^{6}$ through the examination of the changes in three crucial aspects of the self, which are the will (how we want something), recognition (what matters for our sense of worth and self-esteem), and desire (what we long for and how much).

The third chapter identifies the origins and consequences of "commitment phobia", i.e. of "cultural performance around the problem of choice", which can be either hedonic - when commitment is deferred by engaging in a pleasurable accumulation of relationships, and a person cannot fixate on one partner; or aboulic - it is a problem of not wanting anyone, the inability to desire a relationship. The author reconstructs the "new architecture" of romantic choice as mainly the consequence of freedom as the "essential trademark of modernity", because the contemporary exercise of sexual and emotional freedom generates different forms of distress and suffering (feelings of ontological insecurity and meaninglessness).

In the pre-modern marriage markets, choice was shaped by the close interaction of the self with family and the work environment, and ... was binding. Modern marriage markets, in contrast, seem to operate through the seemingly unconstrained, free, and unfettered encounters between people whose faculty of choice is not only exercised, but ongoingly in demand. Yet the faculty of choice, far from being based on pure emotionality, entails a complex affective and cognitive apparatus to evaluate partners, to consult oneself about one's emotions toward them, and to predict one's capacity to sustain these emotions. (p. 90)

The problem is that it is hard to make choices when there is a range of real and imagined options under the collapse of religious, ethnic, racial and class rules of endogamy, and

6. The author uses the term introduced by Karl Polanyi in The Great Transformation (Boston: Beacon Press, 1944) for the economic process by which "the capitalist market dis-embedded economic action from society and from moral/normative frameworks, organized economy in self-regulated markets, and came to subsume society under economy. What we call the 'triumph' of romantic love in relations between the sexes consisted first and foremost in the dis-embedding of individual romantic choices from the moral and social fabric of the group and in the emergence of a self-regulated market of encounters (the role of mass media in defining criteria of attractiveness and worth became significant).... This disentanglement occurred because of a transformation of the content of the criteria for selecting a mate - which have become both physical/ sexual and emotional/psychological - and because of a transformation of the very process of mate selection - which has become both more subjective and more individualized" (p. 41). This great transformation determined that "sexuality, desire, and love had become tightly intertwined with social stratification.... The triumph of love and sexual freedom marked the penetration of economics into the machine of desire" (p. 58). 
one's will and emotions need to be constantly renewed. Moreover, our very capacity to make choices is doubtful because people are ill equipped to engage in "effective forecasting": we cannot be sure about our feelings because of cognitive biases; an extensive process of information gathering to adjudicate between options determines the problem of "information overload", stunts the capacity for strong emotional commitment, tends to dampen the positive appreciation (emotional appeal) of people, and leads to the shift from satisfying (happy with the first available "good enough" option) to maximizing (search for the best possible option, i.e. "pickiness") strategy of choosing the mate.

The fourth chapter reveals the meaning of the demand for recognition of the vulnerable self through love. In pre-modern times, "the center of gravity in courtship referred to propriety, and strongly coded sex and gender conflict; today it focuses on the self disconnected from rank and defined by interiority and emotions . . ; what is at stake for both men and women ... is a view of one's worth as bestowed by others through proper rituals of recognition ... to be in love is to overcome a sense of ordinary invisibility, and entails a sense of uniqueness and an increased sense of self-worth" (p. 112-113). In the nineteenth century, loyalty and commitment were considered crucial testimonies of love, while today they are deemed insufficient and replaced by an ongoing process of "validation", i.e. reconfirmation of one's own individuality and value. "Social worth is no longer a straightforward outcome of one's economic or social status, but has to be derived from one's self, defined as a unique, private, personal, and non-institutional entity. The erotic/romantic bond must constitute a sense of worth, and modern social worth is chiefly performative: it is to be achieved in the course of and through one's interactions with others" (p. 119). The power of romantic love in modernity derives not from the ideology of individualism, but from the fact that it "provides a strong anchor for recognition, perception and constitution of one's worth, in an era where social worth is both uncertain and ongoingly negotiated" (p. 120).

The fifth chapter considers the relations of love, reason and irony under the changing dominant factors of social interactions.

What in earlier age was governed by faith, personal fealty, and charismatic heroes becomes a matter of knowledge, control, and calculable means. This process towards rationalization does not, however, eliminate all manifestations of passion; rather, for Weber, it generates attempts to restore orders of experience dominated by fervor and passion, only vicariously and thinly.... But Weber and others understood rationalization to be opposed to and countered by emotions. . . The challenge for the sociological analysis is to understand rationality and rationalization ${ }^{7}$ not as a cultural logic opposed to emotional life, but rather as working precisely in conjunction with it. Rationality . . . restructured emotional life from within: it

7. Disenchantment follows the rationalization of life conduct which is determined by the prevalence of scientific modes of explaining love (psychoanalytical, psychological, biological and so on), by making love an object of endless investigation, self-knowledge, and self-scrutiny, and by replacement of the Shakespearean "madness of love" by a utilitarian project of securing maximum pleasure and well-being through love (romantic desire was emptied of its mythological content) (p. 162-165). 
has changed the basic cultural scripts through which emotions are understood and negotiated. (p. 158-159)

Today the choice of a mate has become far more rational than before, and we are no longer "dysfunctional love addicts".

Pre-modern rationality involved little or no formal "expert" knowledge; it consisted in a rough evaluation of another's economic assets; beyond general traits of pleasantness, people reflected very little about the desired traits of another; the search was not systematic ... ; it was a group or family search, not an individualized one; ... emotions and self-interest were clearly differentiated categories in martial strategies.... Contemporary actors from adolescence to adulthood develop an elaborate set of criteria for the selection of a mate (social, educational, physical, sexual, and emotional) and very sophisticated means to reach their goals.... A hyper-cognized, rational method of selecting a mate goes in hand with the cultural expectation that love provides authentic, unmediated emotional and sexual experiences. (p. 18o)

Moreover, "the penetration of marketing language and techniques into the realm of interpersonal relationships marks the move to technologies of interchangeability . . that expand the pool of choices, enable the rapid move from one partner to another, and set up criteria for comparing partners ... and oneself to others" (p. 183). Because the options and choices are numerous, changing and rationalized, they determine the uncertainty about the very content of one's feelings and desires, between the norms and estimates of what is actually pleasurable, and such ubiquitous uncertainty generates irony as a dominant trope to discuss love.

The sixth chapter identifies the reasons for romantic fantasy turning into disappointment because of the "regulated, institutionalized, commoditized exercise of imagination" in modern consumer society. In pre-modern times, romantic imagination was a code for the madness which turned love into an irrational and self-generated emotion. "Modern institutions of imagination actively solicit and encourage a low-key form of daydreaming, mostly through the unprecedented production of print and visual media, which provide visual displays of powerful narratives of the good life (utopias of private happiness)" (p. 202). Thus, Tatiana in Pushkin's Eugene Onegin expresses a pre-modern pre-made form of love waiting to be filled by a passing object (the seemingly romantic Eugene), while Flaubert in Madame Bovary prefigures the modern form of love; Emma "cannot distinguish between her love and her images of love, ... her love seems to be nothing but the repetition of empty signs, themselves repeated by the then-emerging cultural industries" (p. 207). "Modern emotions are fictional because of the prevalence of narratives, images, and simulation technologies to engine longing. We have all become Emma Bovarys in the sense that our emotions are deeply embedded in fictional narratives: they develop in stories and as stories" (p. 211). We acquire fictional emotions through our identification with characters and storylines, and the increasing distance between reality and aspirations generates disappointment as a chronic feature of modern lives. 
As the terminology shows, the author prefers a macro-sociological perspective to speak about love and related phenomena (flirting, sexual practices, marriage and divorce). The book considers all types of "the agonies of intimate relationships" (loving someone who will not commit to us, being heartbroken when abandoned by a lover, engaging in a Sisyphean search for one's other half or simpler relations, feeling bored in a relationship which turned into something different from the one we had envisaged, etc.) as "commodities" in the Marxist sense for they are shaped by social relations and institutions and circulate in a marketplace of unequal actors (this is a depressing interpretation of love for those who romanticize it under the massive attack of contemporary movies and love stories in general). "As Karl Marx famously put it, 'Human beings make their history themselves, but they do not do so voluntarily, not under circumstances of their own choosing, rather under immediately found, given and transmitted circumstances'. When we love ..., we do so by using resources and in situations that are not of our own making" (p. 6). "Never before in history have men and women of different social classes, religions, races met as if on a free, unregulated market where attributes of beauty, sexiness, social class are rationally and instrumentally evaluated and exchanged" (p. 242).

The reader may object to such an approach saying that we live in a multifaceted society with a lot more opportunities for individual choice than in the times described by Marx and his followers. However, there is no contradiction because the author's aim is similar to the Marxist idea of liberation by helping us to see that

psychoanalysis and psychotherapy intended or not have provided a formidable arsenal of techniques to make us verbose but inescapable bearers of responsibility for our romantic miseries. ... Precisely because we live in a time where the idea of individual responsibility reigns supreme, the vocation of sociology remains vital. In the same way that at the end of the nineteenth century it was radical to claim that poverty was the result not of dubious morality or weak character, but of systematic economic exploitation, it is now urgent to claim that the failures of our private lives are not the result of weak psyches, but rather the vagaries and miseries of our emotional life are shaped by institutional arrangements. .. . What is wrong in contemporary relationships ${ }^{8}$ are not dysfunctional childhoods or insufficiently self-aware psyches, but the set of social and cultural tensions and contradictions that have come to structure modern selves and identities. (p. 4)

So, let us begin an enumeration of the book's characteristics with the ones mentioned on the back cover. This book is thrilling in its endless possibilities for the sociological analysis of social life because its thematic accents are diverse even within the not-verysociological topic of love. The author "unseats the primacy of individual psychology as

8. As Peter Berger mentioned, the sociologist cannot take any explanation for granted, s/he should consider any phenomenon carefully in order to reveal its hidden preconditions and to see "the general in the particular", i.e. general patterns in the behavior of individuals (Berger P. L. [1963]. Invitation to Sociology: A Humanistic Perspective. New York: Anchor Books). And as Charles Wright Mills emphasized, the sociologist should study social structures in which small milieu are organized, and in our case, in the "milieu" of intimate relationships agonies became too large to seek explanations for the failure of romantic love in individual behavior and psyche (Mills C. W. [1959]. The Sociological Imagination. Englewood Cliffs: Prentice-Hall). 
a reigning explanation for the travails of modern love, and demonstrates the profoundly social nature of our most intimate feelings". The book rejects both biological ${ }^{9}$ and psychological explanations and legitimizations of the difficulties of romantic relations as parts of the problem (the Mars and Venus terminology naturalize the culturally engineered gender differences) and not the answer we seek. Beyond the subjectivity of individuals something fundamental has changed in the institutionalization of the modern cultural category of freedom of choice, which in turn has changed the terms of emotional bargaining of men and women.

Men's and women's romantic unhappiness contains, stages, and enacts the conundrums of the modern freedom and capacity to exercise choice. These conundrums are complexly structured around the following key processes: the transformation of the ecology and architecture of choice; the emergence of sexual fields (social arenas in which sexuality becomes an autonomous dimension of pairing, and which are intensely commodified); new models of recognition (love becomes an aspect of the moral inequalities dynamics ... in one's self-worth ... between the sexes and within one's own sexual group); the cooling of desire and the weakness of will, whose orientation has shifted from the formation of intense bonds to the formation of cool individuality (possessed with irony, commitment phobia, ambivalence, and disappointment). (p. 241-244)

This book is bold in honesty which will not be pleasant or accepted by the majority of readers among both professional sociologists and lay readers (although it is not an easy or entertaining reading). This is a disappointing book for it destroys the illusion of having the sea of individual and group opportunities which contemporary society tries to convince us of. According to the author, today we only seem to have choices such whether to commit or not, to have sexual relations with one partner or many, to love someone temporarily or permanently or to keep out of any relationship at all, to present these choices as rational personal decisions or to consider oneself and others as suffering victims of the circumstances. Our choices are determined by social rules and discourses no less than in previous centuries, yet differently and as if providing us with a range of socially approved scenarios. In pre-modern society, people followed the dictates of their social milieu, and obedience to their parents and community standards was always in the background or foreground of young people's decisions to marry, even if they did not demonstrate that obedience in practice. Today we follow the dictates of our heart, which only sounds nice, for in reality there are social others who tell us what to do and what to feel. In contemporary society, we have psychological counseling, couple therapy (these two being rare in Russia), divorce lawyers, close friends or occasional anonymous friends on the internet all of which constitute "a thick flow of words, self-analysis, and friendly or expert advice". The question is what these people can possibly advise, if they focus on the singular actions and sentiments of individuals and ignore the social structures organizing these actions and sentiments.

9. The intense romantic idealization of a particular partner is determined by serotonin, dopamine and norepinephrine. 
The author emphasizes that the main transformations undergone by love in modernity have affected primarily the conditions within which romantic choices are made. The first group of such conditions concerns the "ecology of choice", i.e. "the social environment that compels one to make choices in a certain direction (for instance, the sexual revolution removed a considerable number of prohibitions on the choice of sexual partner)" (p. 20). The second aspect is the "architecture of choice", i.e. "mechanisms internal to the subject and shaped by culture: they concern both the criteria with which one evaluates an object, and the modes of self-consultation" (p. 21). The latter group of cognitive and emotional processes includes thoughts about the remote consequences of one's decisions, the formality of the consultation used in making a decision, the models of self-consultation (intuitive, habitual knowledge or systematic search and evaluation), cultural norms and techniques to hold one's desires and wants in suspicion, and the accepted grounds for making decisions (the rational or emotional modes of evaluation) ${ }^{10}$. The "loving selves" in the pre-modern world, by modern standards, were emotionally distant, yet inextricably intertwined and interdependent; while the modern "loving selves" "expect each other to be emotionally naked and intimate, but independent. In a modern marriage, it is two highly individuated and differentiated selves that come together; it is the fine-tuned compatibility of two constituted selves that makes up a successful marriage, not the display of roles" (p. 39).

This book is sad and depressing for it claims that love always, invariably and inevitably hurts ${ }^{11}$ despite "the chaos that pervades contemporary romantic and sexual relationships" (p.vii).

In fact, few people living in the contemporary era have been spared the agonies of intimate relationships that come in many shapes: kissing too many frogs on the way to Prince/ss Charming [another problem is lack of guarantees that the Charming does wait for you at the end of the road]; engaging in Sisyphean internet searches; coming back lonely from bars, parties, or blind dates. When relationships do get formed [in cartoons this moment is presented as two loving hearts kissing in a beautiful carriage heading to a happy future], agonies do not fade away, as one may feel bored, anxious, or angry in them; have painful ${ }^{12}$ arguments and conflicts; or, finally, go through the confusion, self-doubts, and depression of break-ups or divorces.... If the sociologist could hear the voices of men and women searching for love, s/he would hear a long and loud litany of moans and groans [this is a rather horrifying picture to imagine]. (p. 3)

Sexual and emotional freedoms as grounds for choosing mates regardless of their social and economic characteristics did not make us free or happy because they are

10. Honestly speaking, this is a depressing approach to love as a "commodity" for sale because our culture romanticized it too much to calmly look at romantic love's "dismembered body".

11. The author does not deny that many people have happy love lives, and warns the readers that the book does not aim to cover exhaustively the many forms which romantic agony takes. However, after finishing the book the reader may wonder if there are many left outside the domain of painful relationships.

12. As the reader may have already noticed the words "pain" and "painful" are more frequent in the review than "love", which certainly reflects the content of the book. 
institutionalized and embedded in a contested but still powerful patriarchy. This has generated new forms of suffering in the shape of inequalities arising from the different ways that men and women feel, experience, and monitor their sexual freedom in competitive sexual fields. Similar to the realm of the market, sexual freedom entails a cultural recording of gender inequalities. ... Sexual freedom made sexuality a site for the exercise and display of masculinity for men whose status in the three arenas of work, home, and male sociability had been eroded: it transformed sexuality into status. ... Sexuality was hypertrophied and merged and expressed at once the three aspects of masculinity as status: authority, autonomy, and solidarity. ... Men are more likely to view the marriage market as a sexual market and tend to stay longer in such a sexual market, whereas women tend to view the sexual market as a marriage market and would tend to stay in it for less time. (p. 61, 73, 78)

One can ask what the point is in reading such a depressing book in the contemporary world which is a hard enough place to survive emotionally without sad books. Well, there are two kinds of sadness - destructive and reviving - and this book is definitely revivingly sad because

understanding the larger set of forces operating on men and women may help avoid the burdens of over-responsibilization. .. . The loss of passion and emotional intensity is an important cultural loss and the cooling of emotions may make us less vulnerable to others, but makes it more difficult to connect to others through passionate engagement. .. Pain hurts but does not kill... Pain emerges as the natural product and natural indicator of being alive in a resistant world. To go through a life painlessly is to have not lived. ${ }^{13}$... Moreover, passionate loves dispels the uncertainty and insecurity inherent in most interactions. (p. 245-246)

The book is also a myth-breaker: it emphasizes the collective character of painful love experiences and accuses the Freudian culture of wrongful and deceitful discourse which declares romantic misery inevitable and self-inflicted, and which blames faulty or insufficiently mature psyches for the agonies of intimate relationships, and forces people to buy countless self-help manuals to better manage romantic lives and erotic careers.

This is a very feminist book already by the question-setting. The author wonders why "despite their strength and autonomy, women . . . are baffled by the elusiveness of men; why men seem to have become a puzzle and an ongoing source of bemusement for wom$e^{14 "}$ (p. vii). Such a feminist emphasis does not turn the book into a politicized women's manifesto against the structural power of men though it argues that "in conditions of modernity men have far more sexual and emotional choice than women" (p. 241). Yet the feminist accent determines a women-biased perception of love and gender relations despite the aim to describe the ways men and women have agonized about love in the past and present, and to question the assumption that love hurts for psychological reasons.

13. Franzen J. (2011). Liking is for Cowards. Go for What Hurts // New York Times. 2011. May 28. Available at: http://www.nytimes.com/2011/05/29/opinion/29franzen.html (accessed 26 November 2017).

14. For instance, in Russia the contemporary folklore emphasizes the role of women as elusive and bemusing for men, as being more emotional, less definite and rarely having a strong opinion compared to men. 
The author believes that the social context of the encounters of men and women explains the ever-painful nature of love, which is proved by the fact that we have been hurt by love since the beginning of the human history, but it is the social conditions that have been changing in the historical development not the nature of the humankind.

Although the book takes the perspective of women, and . . explicates their predicaments, under no circumstance it argues that men do not struggle in love. I have focused on women because they are more familiar terrain for $\mathrm{me}^{15}$; because women have been the endless target of an industry of psychological self-fashioning and urgently need to stop incessantly scrutinizing the so-called 'faultiness' of their psyches; and because I believe emotional suffering is connected - albeit in complex ways - to the organization of economic and political power. (p. 239)

This is also a confusing and thought-provoking book not because it is unclear about some points when describes the changing patterns of love and marriage, but because it uses a slightly unusual demarcation line in the two historical periods in the transformation of love - pre-modern and modern (or late modern) instead of modern and postmodern. The pre-modern (or early modern) love

was governed by the ideals of chivalry, gallantry, and romanticism. . . Women's dispossession of economic and political rights was accompanied (and presumably compensated) by the reassurance that in love they were not only protected by men but also superior to them. It is therefore unsurprising that love has been historically so powerfully seductive for women; it promised them the moral status and dignity they were otherwise denied in society and it glorified their social fate: taking care of and loving others as mothers, wives, and lovers. ... (High or hyper) modernity (the period which followed the World War I) marked the radicalization of the social tendencies inscribed in early modernity, and changed, at times profoundly, the culture of love and the economy of gender identity contained in it. . . . When it put the two political ideals of gender equality and sexual freedom at the center of intimacy, it stripped love of the rituals of deference and the mystical aura in which it had hitherto been shrouded. ... The two most important cultural revolutions of the twentieth century - the individualization of lifestyles and the intensification of emotional life projects; the economization of social relations ... disentangled sex and sexuality from moral norms, and incorporated them in individualized lifestyles and life projects, while the capitalist cultural grammar has massively penetrated the realm of ... romantic relationships. (p. 8-9)

15. The author also mentions that although the book is relevant to many women, it is obviously not relevant to all of them (not to lesbians, or women who are not interested in domesticity or children). The book addresses the condition of love more from the standpoint of those women who opt largely for marriage, reproduction and middle-class lifestyles. Another important analytical limitation of the book is that it considers the Western cultural modernity as "bringing about its own forms of emotional misery and destruction of traditional life-worlds, making ontological insecurity a chronic feature of modern lives, and increasingly impinging in the organization of identity and desire" (p. 13). 
Certainly, the author has every right to choose the terms; however, the word "postmodern" seems to be lacking for two reasons. First, the author admits the increased complexity of contemporary life and mentions "the so-called postmodern subject characterized by a multiplication of desires which result from the institutionalization of imagination" that burdens the individual romantic experience with collective mass-manufactured fantasies (p. 198). For instance, "the modern choice of a mate, based on habitus, or the set of bodily, linguistic, and cultural dispositions acquired during socialization, becomes more complex because it now has to internalize different sets of evaluations, some pulling toward the reproduction of social class, others pulling toward media culture which produces a large array of classless images" (p. 49). The author also describes transformations that are generally recognized as postmodern, such as the ousting of the pre-modern ritualized romantic order (determined by social and economic interest) by the emotionally authentic love practices, in which the intensity and irrationality of one's feelings are an adequate indication of one's true commitment; or the institutional determination of people wanting conflicting goods - "love and autonomy, care and self-reliance ...; culture does not provide a clear sense of hierarchy among competing goods" (p. 97). Postmodernity is the coexistence of pre-modern and modern models: there are as many socially, ethnically, economically or in some other way unequal love-matches as there are marriages of convenience (often happy). For instance, in Russia "residence registration" or an apartment in property often plays the role of the pre-modern woman's dowry and determines her value in the marriage market.

Second, the author ignores (either accidentally or purposefully) such features of the contemporary world as the strange combination of pre-modern, even archaic love and marriage relations (for instance, traditional arranged marriages and illegal but legitimate polygyny are typical for Chechnya) with new forms of cohabitation and marriages (for instance, today gay marriages are legal in 27 countries $^{16}$ ). Another example: the author believes that "dying, committing suicide, and running away to a cloister no longer belong to our cultural repertoires" (p. 2), yet they still do, perhaps partly due to classic literature that presents these extreme practices as an acceptable choice for the unhappy romantic lover. However, the author settles the critique that the book may have unwittingly elicited by repeatedly emphasizing that its ideas (such as the "great transformation of love") are just analytical tools designed to grasp the ways in which the social organization of premodern and contemporary choices differ. The author also defines the limits of empirical generalizations: for instance, commitment phobia is said to be most common in uppermiddle-class men who control social, cultural, and economic resources, and in middleclass educated and economically independent women.

Finally, this book tends to cross the line between fiction and non-fiction in a good way of boundary breaking for it introduces wonderful metaphors and easily recognizable allusions, which is a feature of literature and the arts rather than of the scientific discourse. The author provides illustrative examples from classic literature not only for explana-

16. Gay Marriage Around the World. August, 2017. Available at: http://www.pewforum.org/2017/08/o8/ gay-marriage-around-the-world-2013 (accessed 26 November 2017). 
tion but also to support the "non-academic ambition of the book", which is "to ease the aching of love through an understanding of its social underpinnings. In our times, such a task can begin only if we stop issuing instructions and prescriptions to individuals already overburdened with the tyrannical imperative of living healthy and painless lives and loves" (p. 238). Thus, this is a reassuring book for scholars who love to use examples and quotations from fiction and face the misunderstanding of their colleagues condemning such practices as not sociological or scientific. The author uses many quotes, varying from Ovid's Amores suggesting that the book reflects the reader's passions and private affairs; to John Coetzee wondering in Disgrace if "the young still fall in love, or that mechanism is obsolete by now, unnecessary, quaint ... ; falling in love could have fallen out of fashion" (p.156); to the TV series Sex and the City regarded as "the bible on the modern dysfunctional relationships", and non-fiction works such as Shulamith Firestone's The Dialectic of Sex: The Case for Feminist Revolution emphasizing that "for every successful contemporary love experience, for every short period of enrichment, there are ten destructive love experiences, post-love 'downs' of much longer duration - often resulting in the destruction of the individual, or at least an emotional cynicism that makes it difficult or impossible ever to love again" (p. 1).

The appeal to classic literature is justified in that "it articulates, better than other data, cultural models and ideal types; ... these texts are used not as actual historical documents of romantic practices, but as cultural testimonies of the assumptions that organized the self, morality, and interpersonal relationships of early to mid-nineteenth century" (p. 22). The author provides examples from Emily Brontës Wuthering Heights as an illustration of the long literary tradition portraying love as an agonizing painful emotion if a socially inappropriate match was involved; and from Gustave Flaubert's Madame Bovary as an ironic description of the unhappy marriage of a romantic woman with a kind-hearted man, who cannot satisfy her fantasies. Leo Tolstoy's Anna Karenina could also have appeared in the list of historical examples of love regulated by the social milieu rather by feelings, which led the heroes of such stories to sufferings hardly relevant to modern societies.

In the book, there are many examples from the literary world of Jane Austen for she was "notoriously concerned with matrimony, love, and social status". One of the key aspects of the Austenian world is that

it was impossible to separate the moral norm from the emotional, because it is the moral dimension that organizes emotional lose, which thus has also a public dimension.... The characters' sense of inner self and value is not bestowed in them by anyone, but rather derives from their capacity to recognize and enact moral imperatives ... and bracket their own personal desires ... whether by themselves of by others, in love and in other matters. (p. 25-26)

Jane Austen criticized the rampant self-interest that governed social matchmaking, and promoted affection, mutual respect, and sentiments, albeit grounded in socially accepted norms (rules, codes and rituals of conduct that allowed men and women to be 
proved worthy of each other), but accepted that the woman's self was naturally enmeshed within and protected by her social network and kin. The author calls this ritualized romantic order "a regime of performativity of emotions, i.e. a regime in which emotions are induces by the ritualized actions and expressions of sentiments. ... The fact that love was highly ritualized protected women from the realm of emotion, which could overwhelm them" (p. 30).

Contemporary love practices are illustrated in the book with the quotes from 70 interviews with people living in three large urban centers in Europe, the US, and Israel (a snowball procedure was used); from a variety of web-based support groups; from a large sample of guidebooks to romance, dating, marriage, and divorce; from internet dating sites; and from the New York Times weekly column "Modern Love" for a period of two years. Such a wide range of examples allows the author to explain the specific modern "regime of emotional authenticity": actors know their feelings (either through a great deal of self-scrutiny about the nature and "true" causes of emotions, or through an overwhelming revelation such as "love at first sight"), act on these feelings and use them as the building blocks of a relationship, reveal these feeling to themselves and to others, and make decisions about relationships and commitment based on these feelings. The quotes from the interviews prove the great transformation of romantic love, such as that sexiness became a general trait of personal attractiveness and a central trait in the selection of a mate: "Modern societies offer many more ways for men and women to translate their sexual attractiveness into the field of romance and matrimony" (p. 47); "sexuality became, like beauty, a 'diffuse status characteristic', that is, a characteristic which conferred status" (p. 48).

The examples from the interviews and classic literature supplement and reinforce the author's arguments about endless human suffering, for love always hurts - whether society regulates it or not, whether you prefer to love or to avoid it, whether you strive to find your other half or diligently and successfully avoid such commitments. One can summarize the book's content with the quote from the famous song by Sia expressing the idea of love the reader should get after finishing the book and when feeling hurt by love: "I wanted everything I never had / Like the love that comes with light / I wore envy and I hated that / But I survived / . . You took it all, but I'm still breathing / I knew what I wanted; I went in and got it / . . And I'm still breathing, I'm alive" ${ }^{17}$ (a bit cheesy but very encouraging).

This book is definitely worth reading as an ironic critique of contemporary society that overburdens us with so many musts that we give up the very opportunity of living a full life by fearing or eliminating love as a painful experience. "Under no circumstances does this book make the claim that modern love is always unhappy" (p. 238).

Modern selves are infinitely better equipped to deal with the repeated experiences of abandonment, break-ups, or betrayals than ever in the past through detachment, autonomy, hedonism, cynicism, and irony. In fact, from a young age, most people

17. Written by Sia Furler, Adele Adkins, Tobias Jesso Jr. 
expect the road to romantic love to be a highly bumpy one [I would argue they know that the road can be unpleasant, but hope to avoid it and to have a beautiful and happy road for themselves $\left.{ }^{18}\right]$. . . The point in this book is that because we have developed many strategies to cope with the fragility and the interchangeability of relations, many aspects of contemporary culture deprive the self of the capacity both to enter and to live the full experience of passion and to withstand the doubts and uncertainties attendant to the process of loving and getting attached to someone. Love has changed its form in the sense that it has changed the ways in which it hurts. (p. 240)

This book is humanistic for it declares love to be more than a cultural ideal - it is a constitutive social foundation for the self in a society which lacks the cultural resources necessary for love to fulfill the crucial role of determining self-worth. Therefore,

ethics is urgently demanded back into sexual and emotional relations (though recognizes the necessity of values of freedom, reason, equality, and autonomy), exactly because these relations are now so crucial for the formation of self-worth and self-respect ... Like all waking up after heavy drinking, a sobered endorsement of modernity does not have the fervor of utopias or of denunciation. But it offers the quiet hope that with lucidity and self-understanding, we can better live these times and perhaps even reinvent new forms of passion. (p. 247-248)

This sounds utopian as a social project, but very reassuring for sociology, which has the analytical resources to provide social actors with better self-understanding. "What makes love such a chronic source of discomfort, disorientation, and even despair can be adequately explained only by sociology" which reveals the cultural and institutional core of modernity (p. 12) and links together the individual and the social, "because the contents of thoughts, desires, and inner conflicts have an institutional and collective basis" (p. 12-13).

\title{
Какой должна быть вдохновляющая социологическая книга, или Почему нужно изучать столь неуловимую любовь
}

\author{
Ирина Трочук \\ Доктор социологических наук, ведущий научный сотрудник Центра фундаментальной социологии \\ Национального исследовательского университета «Высшая школа экономики» \\ Доцент кафедры социологии Российского университета дружбы народов \\ Адрес: ул. Мясницкая, д. 20, г. Москва, Российская Федерация 101000 \\ E-mail: irina.trotsuk@yandex.ru
}

Рецензия: Eva Illouz. Why Love Hurts: A Sociological Explanation (Cambridge: Polity, 2016).

18. As Reinhart Koselleck puts it, "in modern times the difference between experience and expectations has increasingly expanded; ... expectations have distances themselves evermore from all previous experience". Quoted in Habermas J. (1990). The Philosophical Discourse of Modernity. Cambridge: MIT Press. P. 12. 